\title{
Psicologia escolar: cenários atuais
}

\section{School psychology: current scenes}

\section{Cynthia Bisinoto Evangelista de Oliveira*}

Doutoranda em Psicologia pela Universidade de Brasília - UNB, Brasília, DF, Brasil

\section{Claisy Maria Marinho-Araújo**}

Professora do Instituto de Psicologia da Universidade de Brasília - UNB, Brasília, DF, Brasil

\begin{abstract}
RESUMO
A articulação da Psicologia com a Educação oportunizou a emergência do psicólogo escolar, profissional que por muito tempo se caracterizou por classificar e ajustar, à escola, os alunos com dificuldades escolares, aplicando o conhecimento psicológico ao contexto escolar. A partir de avanços teóricos e práticos relativos à Psicologia e de uma postura crítica diante da atuação da área nas escolas, a relação Psicologia-Educação se modificou, configurando-se por interdependência de conhecimentos. Nesta nova configuração, a Psicologia Escolar passou a valorizar as relações e o contexto histórico no qual as dificuldades se instalam e, atualmente, caracteriza-se por uma atuação preventiva e relacional que valoriza a participação do professor e o cuidado com sua saúde psíquica. A Psicologia Escolar tem, hoje, o desafio de ampliar seu campo de atuação para outros contextos e níveis educativos e sistematizar ações diferenciadas que promovam o desenvolvimento e a aprendizagem dos envolvidos no cotidiano escolar.
\end{abstract}

Palavras-chave: Psicologia, Educação, Psicologia escolar, Atuação preventiva e síndrome de burnout.

\begin{abstract}
The Psychology and the Education articulations generated the emergence of the school psychologist, professional who had been characterized by classify and adjust, to the school, students with learning difficulties by the application of psychological knowledge to the school context. From theoretical and practical advances relating to psychology and a critical position ahead the area's actuation in schools, the Psychology-Education relationship has changed, configuring itself for an interdependence of knowledge. In this new setting, the School Psychology came to enhance relations and historical context in which the difficulties are established, so that today it's characterized by a preventive and relational perspective, by the teachers' participation and the care for their mental health. The School Psychology has, today, the challenge of to extend its actuation to others contexts and education levels and organize differentiated actions that promote development and learning of people involved in the daily school.
\end{abstract}


Keywords: Psychology, Education, School psychology, Preventive actuation and burnout syndrome.

\title{
A construção da relação psicologia-educação
}

A partir da emergência da Psicologia enquanto área de conhecimento, pesquisa, produção de conhecimento e prática profissional, sua articulação com a Educação passou a se configurar como um dos campos de atuação dos psicólogos, apesar de pouco escolhida pelos profissionais, os quais se detiveram, historicamente, mais ao psicodiagnóstico e à avaliação psicológica (CRUCES, 2003). A inserção da Psicologia nas escolas foi marcada por objetivos fortemente adaptacionistas, nos quais predominava a necessidade de corrigir e adaptar, à escola, o aluno portador de um problema de aprendizagem (CORREI A ; CAMPOS, 2004; TANAMACHI, 2000). Esta adaptação se realizava, no passado, a partir da aplicação de recursos psicométricos, entendidos como função do psicólogo.

O psicodiagnóstico e a avaliação psicológica, dotados de aplicações e técnicas próprias, foram atividades consideradas inerentes e exclusivas do psicólogo, prevalecendo, prioritariamente, nos seus diversos contextos de atuação, inclusive no educacional (CRUCES, 2003). Assim sendo,

\begin{abstract}
a adoção dos instrumentos psicológicos de classificação no interior das instituições educativas se encontra, no nosso país, na origem do que se conhece como a Psicologia Escolar e Educacional. Tais procedimentos refletiam a migração, para o interior da escola, do modelo clínico de atuação e do seu instrumental. (CAMPOS; JUCÁ, 2003, p. 39).
\end{abstract}

Foi, portanto, nesse contexto adaptacionista e de correção, que emergiu a figura do psicólogo escolar ou psicólogo educacional, convocado à escola para resolver problemas que surgiam neste espaço de formação. Um levantamento histórico acerca da atuação do psicólogo escolar constata que

a psicologia, enquanto instrumento aplicado às práticas educacionais, se origina justamente no final do século XIX, com 0 empenho de educadores e cientistas do comportamento em classificarem crianças com dificuldades escolares e proporem às mesmas métodos especiais de educação, a fim de ajustá-las aos padrões de normalidade definidos pela sociedade. (YAZLLE, 1997, p. 15).

No entanto, a aplicação desse modelo médico de intervenção na escola conduziu à patologização e psicologização do espaço escolar por atribuir ao próprio aluno a culpa por suas dificuldades de aprendizagem e por isentar outras instâncias das suas 
responsabilidades educativas (CAMPOS; JUCÁ, 2003; NEVES, 2001; NEVES; ALMEIDA, 2003; YAZLLE, 1997).

Com o passar dos anos e com a revisão crítica acerca da formação e atuação do psicólogo, reformulações e avanços foram dando contorno à área, de forma que os profissionais procuraram não mais se coadunar "à descontextualização e fragmentação do indivíduo, à naturalização dos fenômenos do desenvolvimento humano, à negação do caráter histórico-cultural da subjetividade, à tentativa de 'psicologização' no cenário educacional" (ARAÚJ O, 2003, p. 9).

As mudanças vêm ocorrendo de forma que se encontram, cada vez mais, relatos de experiências de psicólogos que se preocupam em não culpabilizar o aluno pelas dificuldades que enfrenta e tentam conscientizar os demais profissionais de que a problemática do aluno está inserida em uma gama maior de determinantes que não apenas os individuais, os familiares ou os psico-afetivos (CRUCES, 2003; NEVES; ALMEIDA, 2003; NEVES; MACHADO, 2005).

Vê-se, portanto, que o vínculo inicial da relação entre a Psicologia e a Educação, que se caracterizava pela aplicação acrítica das teorias psicológicas às questões educacionais, não se manteve ao longo da história entre esses dois campos científicos, dando lugar a uma relação de interdependência. A aplicabilidade da Psicologia à Educação foi fortemente criticada por não se entender como adequado o uso dos conhecimentos psicológicos para adaptar os alunos à escola, normatizando posturas, princípios e relações de acordo com o que é esperado pela instituição. Além disso, a aplicação dos conhecimentos psicológicos na educação sem a devida reflexão, análise e planejamento, acabavam por gerar processos de exclusão em relação a um conjunto de alunos, uma vez que tais conhecimentos eram apropriados de forma descontextualizada e sem referência à natureza histórico-cultural do ser humano, desconsiderando a realidade social dos alunos e de suas famílias.

A partir de processos de avaliação e reflexão acerca da relação que se estabeleceu entre o conhecimento psicológico e a educação, transformações foram geradas tanto na formação do psicólogo escolar quanto em sua atuação. Como desdobramento deste processo de crítica e reformulação da atuação em Psicologia Escolar, reconhece-se tentativas no sentido de definir o que venha a ser a Psicologia Escolar e de delimitar seu campo de atuação, bem como de apresentar alternativas teórico-práticas que orientem o trabalho dos psicólogos escolares. Sendo assim, a próxima seção traz, inicialmente, reflexões acerca do que seja a Psicologia Escolar e seu campo de atuação e, em seguida, apresenta algumas opções de atuação. 


\section{Psicologia escolar como campo de atuação}

O entrelaçamento entre a Psicologia e a Educação trouxe, para o contexto educativo, um novo profissional: o psicólogo escolar. Entretanto, definir o papel deste profissional e estabelecer seu campo de atuação é uma tarefa complexa, apesar de extremamente necessária, uma vez que co-existem posicionamentos diferentes acerca do que é a Psicologia Escolar. González Rey (1997) e Mitjáns Martínez (2003) apontam que tais diferenças encontram suas raízes na fragmentação da Psicologia, do conhecimento e, conseqüentemente, do indivíduo, em áreas ou partes segmentadas. Tal fragmentação se reflete no debate do que se entende por Psicologia Escolar e sobre quais são as características que a distingue de outros campos e áreas da Psicologia.

Tentando esclarecer tais colocações, Mitjáns Martínez (2003) aponta que "a psicologia escolar é, de fato, a expressão da psicologia (na sua dupla condição de produção científica e de trabalho profissional) no contexto escolar" (p. 107). Nesse sentido, a Psicologia Escolar se refere à Psicologia na escola, com todas as suas possibilidades e implicações no que diz respeito ao processo educativo.

Representando uma intersecção entre a Psicologia e a Educação, o termo Psicologia Escolar se confunde, muitas vezes, com Psicologia Educacional ou Psicologia da Educação. Em relação a estas terminologias, acredita-se, assim como Araújo (2003), que a confusão ocorre em decorrência de concepções dicotômicas entre prática e teoria que atribuem à Psicologia Escolar o caráter prático e à Psicologia da Educação ou Educacional a função da construção de conhecimentos que possam ser úteis ao processo educacional.

Essa distinção que separa teoria e prática traz, como conseqüência, uma dissociação entre o exercício profissional do psicólogo na escola e as elaborações teóricas necessárias a tal exercício. Discordando desta visão dicotômica acredita-se que a Psicologia Escolar define-se como um campo de produção de conhecimentos, de pesquisa e de intervenção e que, entre outras atribuições, assume um compromisso teórico e prático com as questões relativas à escola e a seus processos, sua dinâmica, resultados e atores (MARINHO-ARAÚJO; ALMEIDA, 2005).

Nesse sentido, a Psicologia Escolar é entendida como um campo de atuação profissional do psicólogo e, também, de produção científica, caracterizado pela inserção da Psicologia no contexto escolar, sendo que o objetivo principal deste campo é mediar os processos de desenvolvimento humano e de aprendizagem, contribuindo para sua promoção. Mitjáns Martinez (2003) conceitua a Psicologia Escolar como

um campo de atuação profissional do psicólogo (e eventualmente de produção científica) caracterizado pela 
utilização da Psicologia no contexto escolar, com o objetivo de contribuir para otimizar o processo educativo, entendido este como complexo processo de transmissão cultural e de espaço de desenvolvimento da subjetividade. (p. 107).

Dessa forma, a autora aponta que a especificidade do que se denomina Psicologia Escolar está dada, hoje, pela conjunção de dois elementos: por seu objetivo de contribuir para a promoção do processo educativo e pelo espaço de sua atuação, qual seja o das instituições do sistema escolar, sendo que essas delimitam um espaço que não se reduz à escola, apesar deste ser o espaço fundamental de atuação profissional.

Em relação ao contexto de atuação, alguns autores consideram que o psicólogo escolar se define independentemente do espaço profissional que possa ocupar, enquanto outros assumem que a escola é o espaço preferencial e específico de sua atuação. Meira (2000) e Tanamachi (2000), por exemplo, defendem que o espaço de atuação do psicólogo escolar se estende para outros contextos profissionais que não necessariamente a escola, uma vez que entendem que o psicólogo escolar se define como tal por estar inserido na Educação e não propriamente na escola. Nesse ponto de vista a Psicologia Escolar "enquanto área de estudo e de aplicação dos conhecimentos da Psicologia à Educação escolar efetiva-se menos pela ocupação de um espaço específico - a escola - do que pela definição de objetivos e finalidades" (TANAMACHI, 2000, p. 92).

Por outro lado, Araújo (2003) e Marinho-Araújo e Almeida (2005) discordam das posições que sustentam não ser a escola o espaço preferencial e específico de atuação do psicólogo escolar. A identidade do psicólogo escolar constitui-se "a partir da imersão na escola, enquanto espaço institucional de efetivação concreta da condição humana dos sujeitos participantes e enquanto locus privilegiado para a ocorrência do processo de canalização cultural" (ARAÚJ O, 2003, p. 13).

A identidade do psicólogo escolar e a especificidade de sua atuação são dadas, sobretudo, pela configuração de um campo de atuação profissional, e não por um campo de saberes delimitado por uma abordagem teórica e/ou metodológica. Em sua atuação profissional o psicólogo escolar utiliza múltiplos e diversos conhecimentos, organizados em diferentes áreas da Psicologia, para contribuir com os processos de aprendizagem e de desenvolvimento que ocorrem no contexto escolar (MITJÁNS MARTINEZ, no prelo). Ademais, a especificidade da Psicologia Escolar advém da articulação que o profissional faz dos diversos conhecimentos psicológicos na direção de mediar as relações entre aprendizagem e desenvolvimento que têm lugar no contexto escolar. 
Tendo essa discussão como pano de fundo, assume-se que a escola é o contexto principal de atuação do psicólogo escolar, apesar de não se configurar como o único, uma vez que atuações relevantes em Psicologia Escolar têm se desenvolvido em outros contextos educativos, como é o caso de creches (CAMPOS, 2001; SAYÃO; GUARIDO, 1997; VECTORE; MAIMONE, 2007; YOKOY; PEDROZA, 2005), cursinhos pré-vestibulares (LIMA, 2005; MAYNHONE, SANTOS; MARINHO-ARAÚJ O, 2007; SILVA, COSTA; FERREIRA, 2005; SILVA, RAMOS; NEVES, 2005) e Organizações Não Governamentais ONGs (CARVALHO, 2007; DADICO, 2003; SOARES, 2008).

Pelo exposto, evidencia-se que a atuação da Psicologia Escolar relaciona-se com contextos de natureza educativa nos quais os processos de aprendizagem e de desenvolvimento humano, e a relação que se estabelece entre eles, são tidos como foco do trabalho. A intervenção desencadeada pelo profissional da área voltase, essencialmente, para a mediação desses processos com o objetivo precípuo de promovê-los.

\section{A perspectiva preventiva e relacional como orientadora da atuação em Psicologia Escolar}

Acompanhando a relação estabelecida entre a Psicologia e a Educação, a compreensão contemporânea acerca da atuação em Psicologia Escolar aponta para a necessidade de o psicólogo se comprometer com a modificação do processo de culpabilização e de exclusão dos alunos que prevaleceu como foco de atuação da área em outros momentos históricos. Observa-se a necessidade de ocupar-se da individualidade dos sujeitos sem, contudo, desarticulálos de suas redes de relações e de sua história. Nesse sentido, a perspectiva preventiva em Psicologia Escolar mostra-se como possibilidade de uma atuação diferenciada (ARAÚJ O, 2003; ARAÚJO; ALMEIDA, 2003).

A noção de prevenção está, comumente, relacionada à ação de se antecipar a determinado fenômeno com o objetivo de evitar que ele ocorra e de ajustar soluções a possíveis problemáticas. Todavia, contemporaneamente, a perspectiva preventiva na atuação psicológica busca a superação da visão de promoção de adaptação, esperando que o profissional de Psicologia, em sua intervenção, "evidencie as contradições entre as práticas educativas e as demandas dos sujeitos nesse contexto" (ARAÚjO, 2003, p. 65).

O conceito de prevenção em Psicologia Escolar não se refere ao ajustamento e adequação de situações e comportamentos, tidos como inadequados, a padrões aceitos socialmente, pois esse posicionamento favorável ao controle social, exercido a partir da padronização de comportamentos e atitudes, desconsidera a característica histórica e social de cada indivíduo. A intervenção preventiva proposta contemporaneamente pela Psicologia Escolar 
pretende contribuir para que aconteçam reformulações pessoais e institucionais no sentido de oportunizar, aos atores envolvidos, transformações e saltos qualitativos em seu desenvolvimento. Tais saltos podem ser possíveis através de ações do psicólogo escolar que estejam intencionalmente comprometidas com tal objetivo, como, por exemplo, em relação às concepções dos profissionais da escola acerca da avaliação, da aprendizagem e do desenvolvimento humano. As concepções que os professores têm acerca deste último direcionam sua prática profissional, favorecendo ou prejudicando sua mediação em relação ao desenvolvimento psicológico de seus alunos. Conhecer e intervir sobre as concepções de natureza deterministas e reducionistas dos professores, por exemplo, é uma possibilidade de contribuir para a transformação de práticas que se mantêm rígidas e imutáveis independentemente dos sujeitos envolvidos. Intervir nas concepções que são balizadoras das ações e práticas dos profissionais é uma forma de promover mudanças neles e, provavelmente, nos alunos também, contribuindo para que tenham oportunidade de rever seus conceitos e práticas, retomar suas prioridades, modificar suas intenções e objetivos, reconsiderar seu papel na formação dos alunos, entre outros.

Ao contrário da visão de controle, a atuação preventiva em Psicologia Escolar deve estar respaldada em ações que busquem a) facilitar e incentivar a construção de estratégias de ensino diversificadas, b) promover a reflexão e a conscientização de funções, papéis e responsabilidades dos sujeitos e c) superar, junto com a equipe escolar, os obstáculos à apropriação do conhecimento (MARINHOARAÚJ O; ALMEIDA, 2005).

Dessa forma, a ação preventiva deve ser redirecionada para a compreensão e intervenção nas relações interpessoais que permeiam a construção do conhecimento e da ação pedagógica, sendo preciso que o psicólogo escolar instrumentalize-se para estudar e entender as relações interpessoais como sendo sua unidade de análise, isto é, seu foco de atenção e de intervenção (ARAÚJ O, 2003; ARAÚJ O; ALMEIDA, 2003; MARINHO-ARAÚJ O; ALMEIDA, 2005).

Corroborando a perspectiva relacional, Machado (2000) lembra que "não existem causas individuais para os fenômenos da vida, pois eles não são individuais, não são de ninguém. São efeitos que se engendram em uma rede de relações" (p. 146). Por assim ser, entende-se que os fenômenos são viabilizados nas relações e, dessa maneira,

os caminhos para a intervenção do psicólogo escolar devem, portanto, estar ancorados na compreensão de que as relações sociais originam o processo interdependente de construções e apropriações de significados e sentidos que acontece entre os indivíduos, influenciando, recíproca e/ou complementarmente, como cada sujeito constitui-se 
enquanto tal. Para intervir na complexidade intersubjetiva presente nessas relações, o psicólogo deve fazer uma escolha deliberada e consciente por uma atuação preventiva sustentada por teorias psicológicas cujo enfoque privilegie uma visão de homem e sociedade dialeticamente constituídos em suas relações históricas e culturais. (ARAÚjO, 2003, p. 66).

Sendo assim, faz-se extremamente necessário abandonar as concepções e práticas que entendem os fenômenos educativos sobre o prisma individual e dissociado do contexto histórico-social no qual está inserido, devendo se encaminhar para a adoção de concepções relacionais, integradoras e amplas.

Embasada na perspectiva preventiva e relacional em Psicologia Escolar (ARAÚJO, 2003; ARAÚJO; ALMEIDA, 2003) e na perspectiva histórico-cultural (VYGOTSKY, 2003), uma das propostas contemporâneas de atuação da área refere-se à inclusão do professor como co-participante das atuações em Psicologia Escolar.

Nesta proposta, acredita-se que a inclusão de diferentes atores na intervenção de um problema escolar é a maneira mais adequada de se promover o desenvolvimento e a aprendizagem. Nesse sentido, Neves e Almeida (2003) apontam que, ao se colocar o professor como co-participante no processo de atendimento a seus alunos, por exemplo, emerge um espaço de interlocução que possibilita ao professor refletir sobre sua prática e assumir uma postura mais crítica diante das queixas escolares.

Com a participação do professor, além de trocar informações, "os psicólogos escolares podem criar condições para a desmistificação das explicações psicologizantes, a partir de uma reflexão consistente e fundamentada nos conhecimentos acumulados pela Psicologia" (MEIRA, 2000, p. 66). A participação ativa do professor na busca de alternativas para o efetivo aprendizado dos alunos the possibilita apropriar-se de sua função e responsabilidade, as quais, por algum tempo, foram delegadas ao psicólogo ou a outros "especialistas" que se ocupavam dos fenômenos educativos. Dessa forma, acredita-se que é possível contribuir para "o resgate do papel ativo e dirigente do professor (...) na reflexão, estudo e posterior definição dos caminhos e recursos necessários à resolução das dificuldades" (MEIRA, 2000, p. 66), a partir de sua inclusão na discussão e reflexão acerca das dificuldades identificadas.

Por meio da participação do professor, o psicólogo escolar pode favorecer processos de questionamento e de conscientização acerca das concepções deterministas de desenvolvimento e aprendizagem que, implicitamente e de forma pouco lúcida, ainda estão presentes nas compreensões das queixas escolares e, portanto, nas práticas pedagógicas. 


\section{A atenção ao professor como espaço de intervenção em Psicologia Escolar}

O professor é considerado o principal agente do processo educacional, co-participante e mediador da intervenção junto às dificuldades escolares, de forma que em virtude deste importante papel diversas propostas de formação continuada são elaboradas com vistas a promover o desenvolvimento profissional dos professores. Os inúmeros esforços nesse sentido sustentam-se sobre a intenção de que os docentes estejam cada vez mais cientes das possibilidades e estratégias de trabalho que podem adotar em prol do desenvolvimento e da aprendizagem de seus alunos. Contudo, a qualidade da atividade desses profissionais depende, também, do seu bem-estar, de forma que ao psicólogo escolar cabe, do mesmo modo, responsabilizar-se pela promoção da saúde mental dos docentes.

Por esse motivo, ao se trabalhar junto com os professores é preciso levar em conta diferentes questões que dificultam a atuação adequada destes profissionais, refletindo e discutindo sobre alguns aspectos que afetam a saúde e a qualidade de vida do professor e da sua profissão. Um desses aspectos refere-se ao burnout, síndrome vivenciada por muitos professores em decorrência da natureza da atividade que realizam.

Todo trabalho envolve algum investimento afetivo por parte do trabalhador, seja na relação com os outros ou com o produto do trabalho, sendo que o diferencial do trabalho docente está no fato de que "a relação afetiva é obrigatória para o exercício do trabalho, é um pré-requisito" (CODO; GAZZOTTI, 1999, p. 50). A afetividade é um conjunto de fenômenos psíquicos que se manifestam sob a forma de emoções e sentimentos, sempre acompanhados de dor ou prazer, satisfação ou insatisfação, alegria ou tristeza, entre outros (CODO; GAZZOTTI, 1999). A relação entre a afetividade e o trabalho docente configura-se, portanto, como uma relação necessária, sendo que para que o professor consiga desempenhar satisfatoriamente seu trabalho é preciso que seja estabelecida uma relação afetiva com seu aluno. Todavia, quando o vínculo afetivo não se concretiza de forma satisfatória nas relações formais de trabalho, instala-se uma contradição junto ao trabalhador.

A contradição entre a necessidade de se vincular afetivamente na relação profissional e a impossibilidade dessa vinculação se concretizar totalmente é responsável pelos conflitos de sentimentos presentes na vida do professor. De acordo com Codo e Gazzotti (1999), na maioria das vezes esse conflito não é percebido pelo professor, é invisível; trata-se, na verdade, de uma vivência subjetiva que o próprio professor não percebe que está sentindo. Pela impossibilidade de vincular-se afetivamente, na medida desejada, a afetividade que seria dirigida ao seu destinatário, o aluno, por exemplo, acaba sendo redirecionada. 
Já que não é possível investir o aluno com o afeto desejado, este acaba sendo voltado para o próprio corpo do trabalhador, e isso traz conseqüências bastante negativas para os nossos educadores. Quando a mente não vai bem o corpo padece, já dizia um velho ditado. (CODO; GAZZOTTI, 1999, p. 58).

Por essas razões, diz-se que é relativamente freqüente perceber os profissionais da educação como agentes de alto risco, sendo várias as queixas que denunciam situações de mal-estar docente (ALMEIDA; FIGUEIRA， 1998; BENEVIDES-PEREIRA， 2002; CODO; VASQUESMENEZES, 1999). Este mal-estar foi inicialmente descrito a partir do termo inglês burnout, utilizado para designar os professores cansados, abatidos, sem vontade de ensinar e que já desistiram desta tarefa. Em português, o significado deste termo gira em torno de "perder o fogo", de "perder a energia" ou de "queimar" e diz respeito à "síndrome através da qual o trabalhador perde o sentido da sua relação com o trabalho, de forma que as coisas já não o importam mais e qualquer esforço lhe parece ser inútil" (CODO; VASQUES-MENEZES, 1999, p. 238).

A síndrome é multidimensional e envolve três componentes interrelacionados: a) a exaustão emocional, em que os trabalhadores sentem que não podem dar mais de si mesmos a nível afetivo; b) despersonalização, em que ocorre o desenvolvimento de sentimentos e atitudes negativas em relação aos alunos; e c) falta de envolvimento pessoal no trabalho, situação marcada por uma evolução negativa no trabalho que afeta as habilidades envolvidas na realização do mesmo (ALMEIDA; FIGUEIRA, 1998; CODO; VASQUESMENEZES, 1999).

As repercussões ou conseqüências do burnout são sentidas pelo professor e pelos alunos, demonstrando que o mal-estar vivido pelo docente em relação à sua profissão enfraquece a relação professoraluno e os processos de ensino e de aprendizagem. O burnout compromete, igualmente, a saúde do professor e a qualidade do aprendizado dos alunos, indicando a necessidade de intervenções que minimizem o sofrimento docente e possibilitem espaços e relações adequadas ao aprendizado. Diante dessa necessidade o psicólogo escolar pode estabelecer um contexto de atuação relacionado à promoção da saúde mental, pautando-se na identificação de fatores institucionais, por exemplo, que estão comprometendo e dificultando o trabalho docente.

A proposta da Psicologia Escolar no que se refere ao burnout docente difere da perspectiva terapêutica ou clínica que pode ser realizada em outros contextos. A intervenção do psicólogo escolar junto a esta síndrome deve ser coerente com a perspectiva preventiva já explicitada anteriormente, privilegiando, portanto, que as 
contradições entre as demandas dos sujeitos e as práticas e rotinas institucionais definidas no contexto escolar sejam evidenciadas, e não camufladas, como forma de possibilitar a circulação de necessidades, exigências, incertezas, expectativas, angústias, possibilidades, limitações, entre outras. A criação de um espaço de interlocução, mediado pelo psicólogo escolar, visa oportunizar a circulação dos sentidos, compartilhar vivências e promover o bem-estar dos professores, sua saúde mental e, assim, prepará-los para sua atividade profissional.

Nota-se, portanto, a importância de o psicólogo escolar estar atento ao sofrimento vivenciado pelos professores, os quais são os grandes motores dos processos educacionais, mas que, diariamente, estão sujeitos à exaustão emocional, a sentimentos de desgaste e de incerteza, entre outros, distanciando-se da sua tarefa de educar as crianças e jovens sob sua responsabilidade.

\section{Considerações finais}

A Psicologia Escolar, enquanto campo de produção científica e de atuação profissional do psicólogo, caracteriza-se pela inserção da Psicologia no contexto escolar com o objetivo de contribuir para a promoção do desenvolvimento, da aprendizagem e da relação entre esses dois processos.

Inserido neste contexto de formação coube ao psicólogo escolar, por muito tempo, classificar os alunos com dificuldades escolares e propor métodos especiais de educação, tentando ajustá-los aos padrões de normalidade aceitos socialmente. Entretanto, a partir do afastamento em relação à postura adaptativa e corretiva, a Psicologia Escolar tem buscado solidificar uma atuação de caráter preventivo e relacional que se sustenta muito mais em parâmetros de sucesso do que de fracasso. Conforme pontuam Neves e Almeida (2003), o fracasso escolar no Brasil configura-se como um grave problema social que demanda contribuições das diversas áreas do conhecimento, sendo que do ponto de vista da Psicologia essa contribuição torna-se relevante quando se ultrapassam as práticas conservadoras que tratam o fracasso do aluno como um problema individual ou do seu meio familiar.

O fracasso escolar carrega, em sua base, a responsabilização (ou culpabilização) ao próprio aluno e à sua família, das dificuldades que vivencia em relação ao aprendizado escolar, enfatizando as limitações e deficiências que, supostamente, o aluno teria. A cultura do sucesso escolar, por outro lado, privilegia as potencialidades e possibilidades em vez dos problemas e dificuldades, focaliza as diferentes alternativas individuais e coletivas de superação das adversidades, valoriza as diferenças, a heterogeneidade e a diversidade de formas de aprender, pensar e estar no mundo. Nesse sentido, a Psicologia Escolar tem buscado consolidar uma atuação que se baseia em 
crescimento e sucessos dos atores escolares em contraponto à ênfase em problemas e dificuldades.

Nessa nova perspectiva de atuação, tenta-se criar espaços de interlocução com todos os atores escolares, incluindo e acolhendo os diferentes segmentos que participam e constroem o cotidiano escolar. Esses espaços têm como foco tanto os aspectos objetivos dos processos de desenvolvimento e de aprendizagem, como a conscientização dos aspectos subjetivos que os permeiam.

Imersa em um contexto social cheio de transformações, a Psicologia Escolar tem construído atuações que buscam não somente abandonar um modelo que focaliza o problema no aluno. Ela tem se esforçado para integrar outras modalidades de trabalho que ampliem as possibilidades de sucesso dos atores envolvidos, superando as práticas psicológicas que tratam a dificuldade de aprendizagem ou 0 fracasso escolar como um problema individual ou do meio familiar.

Uma das novidades na prática da Psicologia Escolar é a participação do professor no processo de acompanhamento dos alunos quando dificuldades escolares são identificadas. A inserção desse profissional na parceria com o psicólogo escolar traz um importante diferencial às ações desenvolvidas nas escolas: a possibilidade dos professores se perceberem participantes ativos e co-construtores dos processos de sucesso escolar, à medida que se apropriam de sua função e responsabilidade profissional.

Outra frente de trabalho do psicólogo escolar junto aos professores é a atenção à sua saúde psíquica. Em virtude do forte vínculo afetivo, do intenso investimento no outro (o aluno) e da expectativa em relação aos resultados de seu trabalho, é comum identificar professores cansados, abatidos e desmotivados diante da tarefa de ensinar. Tais situações caracterizam professores que sofrem da síndrome de burnout e que precisam da intervenção do psicólogo escolar (e de outros profissionais de saúde) para modificar este quadro de sofrimento e reencontrar o prazer e alegria de ensinar.

Importante destacar que atuação da Psicologia Escolar na perspectiva preventiva e relacional aqui apresentada, não se limita apenas às escolas, apesar do profissional da área ser comumente associado a ela por este ter sido o contexto no qual, historicamente, se consolidou a relação entre a Psicologia e a Educação. Apesar de um grande número de pesquisas em Psicologia Escolar ter como objeto de estudo questões que permeiam o cotidiano da escola, como as dificuldades de aprendizagem, a relação professor-aluno, a inclusão escolar, a relação família-escola, a criatividade, entre outros, a referência às instituições do sistema escolar delimita um espaço de atuação e de pesquisa que não se reduz à escola.

Dessa forma, a Psicologia Escolar tem, entre os seus desafios, ampliar seu foco de atuação, pesquisa e produção de conhecimento para além da escola, pois diferentes contextos como creches e ONGs, 
por exemplo, e outros níveis do sistema educacional podem enriquecer-se do trabalho desenvolvido por profissionais e pesquisadores voltados à interface Psicologia-Educação.

Diante deste novo cenário que vem caracterizando a Psicologia Escolar contemporânea, espera-se construir ações diferenciadas e transformadoras que, além de promoverem o desenvolvimento e a aprendizagem de todos os envolvidos no cotidiano escolar, venham também a enriquecer esse campo do conhecimento.

\section{Referências Bibliográficas}

ALMEIDA, A. C.; FIGUEIRA, A. P. C. O psicólogo no processo de desenvolvimento pessoal e profissional dos professores: razões justificadas da criação de uma Estrutura de Apoio Psicopedagógico a professores. Revista Portuguesa de Pedagogia, ano XXXII, $\mathrm{n}^{\circ} 3$, 1998. p. 69-97.

ARAÚjO, C. M. M.; ALMEIDA, S. F. C. de. Psicologia Escolar Institucional: desenvolvendo competências para uma atuação relacional. In: ALMEIDA, S. F. C. de (Org.). Psicologia Escolar: Ética e competências na formação e atuação profissional. Campinas: Editora Alínea, 2003. p. 59-82.

ARAÚjO, C. M. M. Psicologia Escolar e o Desenvolvimento de Competências: uma opção para a capacitação continuada. 2003. 395 f. Tese (Doutorado em Psicologia). Instituto de Psicologia, Universidade de Brasília, Brasília.

BENEVIDES-PEREIRA, A. M. T. Burnout: o processo de adoecer pelo trabalho. In: BENEVIDES-PEREIRA, A. M. T. (Org.). Burnout: quando o trabalho ameaça o bem-estar do trabalhador. São Paulo: Casa do Psicólogo, 2002. p. 21-91.

CAMPOS, A. P. S. F. M. O Psicólogo Escolar e a Educação Infantil: um olhar sobre a inserção desse profissional nas escolas de Brasília. 2001. 193 f. Dissertação (Mestrado em Psicologia). Universidade de Brasília, Brasília.

CAMPOS, H. R.; JUCÁ, M. R. B. L. O psicólogo na escola: avaliação da formação à luz das demandas do mercado. In: ALMEIDA, S. F. C. de (Org). Psicologia Escolar: ética e competências na formação e atuação profissional. Campinas: Editora Alínea, 2003. p. 37-56.

CARVALHO, T. O. de. Atuação em Psicologia Escolar: o Desenvolvimento de Competências para Mediação da Orientação Profissional de Adolescentes em São Luís-MA. 2007. 181 f. Dissertação (Mestrado em Psicologia). Universidade de Brasília, Brasília.

CODO, W.; GAZZOTTI, A. A. Trabalho e afetividade. In: CODO, W. (Org.). Educação: carinho e trabalho. Petrópolis: Vozes, 1999. p. 48-59. 
CODO, W. ; VASQUES-MENEZES, I. O que é burnout? In: CODO, W. (Org.). Educação: carinho e trabalho. Petrópolis: Vozes, 1999. p. 237-254.

CORREI A, M.; CAMPOS, H. R. Psicologia Escolar: histórias, tendências e possibilidades. In: YAMAMOTO, O. H.; NETO, A. C. (Orgs.). O psicólogo e a escola: uma introdução ao estudo da psicologia escolar. Natal: EDUFRN, 2004. p. 137-185.

CRUCES, A. V. V. Psicologia e Educação: nossa história e nossa realidade. In: ALMEIDA, S. F. C. de (Org.). Psicologia Escolar: ética e competências na formação e atuação profissional. Campinas: Editora Alínea, 2003. p. 17-36.

DADICO, L. Atuação do psicólogo em Organizações NãoGovernamentais na área da educação. 2003. 180 f. Dissertação (Mestrado em Psicologia). Universidade de São Paulo, São Paulo.

GONZÁLEZ REY, F. Epistemologia cualitativa y subjetividad. São Paulo: Educ, 1997.

LIMA, P. F. DE S. Atuação do psicólogo escolar/educacional em um programa de orientação profissional de um cursinho pré-vestibular gratuito. In: Resumos da XI Reunião Anual da Sociedade de Psicologia do Triângulo Mineiro. Uberlândia: SPTM, 2005.

MACHADO, A. M. As crianças excluídas da escola: um alerta para a psicologia. In: MACHADO, A. M.; PROENÇA, M. (Orgs.). Psicologia escolar: em busca de novos rumos. São Paulo: Casa do Psicólogo, 2000. p. 39-54.

MARINHO-ARAÚ O, C. M.; ALMEIDA, S. F. C. de. Psicologia escolar: construção e consolidação da identidade profissional. São Paulo: Editora Alínea, 2005.

MAYNHONE, T. R. R., SANTOS, R. A. DOS; MARINHO-ARAUJ O, C. M. Estágio em Psicologia Escolar: curso preparatório para o vestibular como um possível campo de atuação do psicólogo escolar. In: Anais do VIII Congresso Nacional de Psicologia Escolar e Educacional. Minas Gerais: ABRAPEE, 2007. p. 190.

MEIRA, M. E. M. Psicologia Escolar: pensamento crítico e práticas profissionais. In: TANAMACHI, E. de R., PROENÇA, M. ; ROCHA, M. L. da (Orgs.). Psicologia e Educação: desafios teórico-práticos. São Paulo: Casa do Psicólogo, 2000. p. 35-71.

MITJÁNS MARTÍNEZ, A. O psicólogo na construção da proposta pedagógica da escola: áreas de atuação e desafios para a formação. In: ALMEIDA, S. F. C. de (Org.). Psicologia Escolar: ética e competências na formação e atuação profissional.. Campinas: Editora Alínea, 2003. p. 105-124.

MITJÁNS MARTINEZ, A. O que pode fazer o psicólogo na escola?: contribuições da psicologia no contexto escolar. No prelo.

NEVES, M. M. B. da J. A Atuação da Psicologia nas Equipes de Atendimento Psicopedagógico da Rede Pública de Ensino do 
Distrito Federal. 2001. 196 f. Tese (Doutorado em Psicologia). Instituto de Psicologia, Universidade de Brasília, Brasília.

NEVES, M. M. B. DA J.; ALMEIDA, S. F. C. de. A atuação da Psicologia Escolar no atendimento aos alunos encaminhados com queixas escolares. In: ALMEIDA, S. F. C. de (Org.). Psicologia Escolar: Ética e competências na formação e atuação profissional. Campinas, SP: Editora Alínea, 2003. p. 83-103.

NEVES, M. M. B. DA J. ; MACHADO, A. C. A. Psicologia Escolar e Educação Inclusiva: novas práticas de atendimento às queixas escolares. In: MITJÁNS MARTÍNEZ, A. (Org.) Psicologia Escolar e Compromisso Social. Campinas, SP: Editora Alínea, 2005. p. 135151.

SAYÃO, Y. ; GUARIDO, R. L. Intervenção Psicológica em creche/ préescola. In: MACHADO, A. M.; SOUZA, M. P. R de (Orgs.). Psicologia Escolar: em busca de novos rumos. São Paulo: Casa do Psicólogo, 1997. p.79-88.

SILVA, D. L., COSTA, A. M.; FERREIRA, A. M. DOS S. Pré-Vestibular Reconhecimento: desafios para a Psicologia Escolar. In: Anais do VII Congresso Nacional de Psicologia Escolar e Educacional. Curitiba: ABRAPEE, 2005. Disponível em <http://www.conpe.popba.rnp.br/>. Acesso em: 15 de agosto de 2008.

SILVA, D. L., RAMOS, L. C.; NEVES, T. I. Atuação em Psicologia Escolar/Educacional no Pré-vestibular comunitário Re-Conhecimento. In: Anais do VII Congresso Nacional de Psicologia Escolar e Educacional. Curitiba: ABRAPEE, 2005. Disponível em $<$ http://www.conpe.pop-ba.rnp.br/>. Acesso em: 15 de agosto de 2008.

SOARES, P. G. Psicologia Escolar e Desenvolvimento Adulto: um estudo sobre o perfil de educadoras sociais em uma ONG de São Luís/ MA. 2008. 245 f. Dissertação (Mestrado em Psicologia). Instituto de Psicologia, Universidade de Brasília, Brasília.

TANAMACHI, E. de R. Mediações teórico-práticas de uma visão crítica em psicologia escolar. In: TANAMACHI, E. de R., PROENÇA, M. ; ROCHA, M. L. da (Orgs.). Psicologia e Educação: desafios teórico-práticos. São Paulo: Casa do Psicólogo, 2000. p. 73-103.

VECTORE, C.; MAIMONE, E. H. A formação do psicólogo escolar e a atuação em instituições infantis: da história às práticas atuais. In: HERCULANO, R. C. (Org.). Formação em Psicologia Escolar: realidades e perspectivas. Campinas, SP: Editora Alínea, 2007. p. 135- 147.

VYGOTSKY, L. S. A Formação Social da Mente. São Paulo: Martins Fontes, 2003.

YAZLLE, E. G. Atuação do psicólogo escolar: alguns dados históricos. In: CUNHA, B. B. B., YAZLLE, E. G., SALOTTI, M. R. R.; SOUZA, M. De (Orgs.). Psicologia na Escola: um pouco de história e algumas histórias. São Paulo: Arte ; Ciência, 1997. p. 11-38. 
YOKOY, T.; PEDROZA, R. L. S. Psicologia Escolar em educação infantil: reflexões de uma atuação. Psicologia Escolar e Educacional, vol. 9, № 1, 2005. p. 95-104.

\section{Endereço para correspondência}

Cynthia Bisinoto Evangelista de Oliveira

Universidade de Brasília, Instituto de Psicologia, Campus Darcy Ribeiro, ICC Sul, Bloco A, CEP 70.910-900, Brasília-DF, Brasil

Endereço eletrônico: cynthia.b@uol.com.br

Claisy Maria Marinho-Araújo

Universidade de Brasília, Instituto de Psicologia, Campus Darcy Ribeiro, ICC Sul, Bloco A, CEP 70.910-900, Brasília-DF, Brasil

Endereço eletrônico: claisy@unb.br

Recebido em: 12/01/2009

Aceito para publicação em: 04/08/2009

Acompanhamento do processo editorial: Adriana Benevides Soares

\section{Notas}

* Psicóloga Escolar, Mestre

** Psicóloga, Doutora em Psicologia 